\title{
Can Confucius lose face in the era of mass surveillance?
}

\author{
Ho Manh Tung \\ Ritsumeikan Asia Pacific University \\ Beppu, Oita, Japan
}

Sept 16, 2020

Philosopher Philip J. Ivanhoe (2020) argues in an Aeon essay that in China's mass surveillance state, with facial recognition being the main apparatus of social control, the society will move away from the traditional notion of the face.

In traditional Chinese thought, the face has two meanings: one is about moral character, and the other is about social status. The two interact with each other; for example, having a good moral character will eventually contribute to one's social standing. And building a good moral character, in Chinese philosophy, is the idea of self-cultivation, of training your moral sense to achieve a proper sense of shame and sincerity. This requires deep reflection, which means having space and the ability to look inwards, and evaluate one's thoughts, behaviors, and emotions, and shape them according to moral ideals. Ivanhoe argues the modern mass-surveillance state robs people of the opportunities for exercising this process of self-cultivation. Instead, facial recognition technology forces people to react to the presence of an unrelenting gaze. They have to watch themselves constantly.

It seems to me we have to put Ivanhoe's argument into a larger context. There are four contexts I find relevant here. First, the notion of privacy, if any, in Confucian culture needs to be understood. In Chinese philosophy, there is no concept that directly translates to privacy as a 
moral right of freedom from surveillance and state interference, commonly conceived in the West (Whitman, 1985).

Second, in Chinese philosophies, the government's role is not conceived minimally like in the West. Confucian thoughts view the government, at its best, should be a good influence on the moral behavior of the citizen (Whitman, 1985).

Third, scholarly works on the phenomenon of "cultural additivity" have shown the Confucian system of values can strongly accommodate other values (Vuong et al., 2019; Vuong et al., 2018; Vuong et al., 2020). This suggests that Western values of privacy will be adopted and adapted to the mainstream Confucian system of values. There is already a market force at play to sell privacy as a consumer good (Wang \& Yu, 2015).

Finally, it is important to always keep in mind the resilience of the people and their desire for self-improvement. In terms of resilience, the clearest examples are the risky business of online political satire in China and the subverting political propaganda through daily jokes (Tang \& Yang, 2011; Yang \& Jiang, 2015; Yang, Tang, \& Wang, 2015). In terms of the desire for selfimprovement, a clear example is a growth of self-help literature in China (Yang, 2017).

With these contexts in mind, we can evaluate the argument of Ivanhoe (2020) better. The key idea in his argument is self-cultivation, which Ivanhoe believes will be damaged due to the arrival of mass surveillance. The phrase "Confucius loses face" captures this point. The fourth context suggests people will continue to do what they think will improve themselves and criticizing social and political vibes, albeit covertly. This means there will always be a degree of self-cultivation. It might be noteworthy here is that in Chinese philosophies, self-cultivation's 
ultimate goal is "tranquility": the ability to adapt to whatever might come and to understand what one's natural role in life and society is, which will result in harmony.

The first three contexts suggest whether Confucius really loses face depends less on technologies but how "cultural additivity" works in the modern Chinese society: whether the Western ideals of an individual self, limited government, and privacy could take roots and overwhelm the traditional Confucian conception of life and society. But that, for me, is unlikely. After all, Confucian thoughts have been present in every aspect of Chinese society for thousands of years.

\section{References}

Ivanhoe, P. (2020). How Confucius loses face in China's new surveillance regime. Aeon, Psyche. Retrieved from https://aeon.co/ideas/how-confucius-loses-face-in-chinas-new$\underline{\text { surveillance-regime }}$

Tang, L., \& Yang, P. (2011). Symbolic power and the internet: The power of a 'horse'. Media, Culture \& Society, 33(5), 675-691.

Vuong, Q.-H., Bui, Q.-K., La, V.-P., et al. (2019). Cultural evolution in Vietnam's early 20th century: A Bayesian networks analysis of Hanoi Franco-Chinese house designs. Social Sciences \& Humanities Open, 1(1), 100001.

Vuong, Q.-H., Bui, Q.-K., La, V.-P., et al. (2018). Cultural additivity: behavioural insights from the interaction of Confucianism, Buddhism and Taoism in folktales. Palgrave Communications, 4(1), 143. 
Vuong, Q.-H., Ho, M.-T., Nguyen, H.-K. T., et al. (2020). On how religions could accidentally incite lies and violence: folktales as a cultural transmitter. Palgrave Communications, $6(1), 82$.

Wang, Z., \& Yu, Q. (2015). Privacy trust crisis of personal data in China in the era of Big Data: The survey and countermeasures. Computer Law \& Security Review, 31(6), 782-792.

Whitman, C. B. (1985). Privacy in Confucian and Taoist thought. In D. Munro (Ed.), Individualism and Holism: Studies in Confucian and Taoist Values. Ann Arbor: Univ. of Michigan, Center for Chinese Studies.

Yang, G., \& Jiang, M. (2015). The networked practice of online political satire in China: Between ritual and resistance. International Communication Gazette, 77(3), 215-231.

Yang, J. (2017). Virtuous power: Ethics, Confucianism, and psychological self-help in China. Critique of Anthropology, 37(2), 179-200. doi:10.1177/0308275X17694943

Yang, P., Tang, L., \& Wang, X. (2015). Diaosi as infrapolitics: Scatological tropes, identitymaking and cultural intimacy on China's Internet. Media, Culture \& Society, 37(2), 197214. 